\title{
PANDUAN PERENCANAAN KARIER BERBASIS PRINSIP HIDUP TOMA LOA SE BANARI SISWA SMA
}

\author{
Sukria Ahsan $^{1}$, IM Hambali ${ }^{2}$, Nur Hidayah ${ }^{3}$ \\ ${ }^{1}$ Universitas Khairun \\ ${ }^{2,3}$ Universitas Negeri Malang
}

\begin{tabular}{|c|c|}
\hline & Abstract \\
\hline \multirow[t]{2}{*}{$\begin{array}{l}\text { Keywords: } \\
\text { Career planning, } \\
\text { life principles of } \\
\text { toma loa se banari } \\
\text { and high school } \\
\text { students. }\end{array}$} & $\begin{array}{l}\text { The purpose of this study was to produce a description of the content and format of a } \\
\text { career planning guide based on the life principles of toma loa se banari that is } \\
\text { suitable for helping high school students plan their careers. The method used in this } \\
\text { research is research and development using stages from Borg and Gall. The } \\
\text { instruments used in this study were (1) expert assessment instruments (2) user } \\
\text { assessment instruments and ( } 3 \text { ) career planning scales. The final result of this } \\
\text { research is a product which is a career planning handbook based on the life principle } \\
\text { of Toma Loa Se Banari that meets the elements of acceptance consisting of aspects } \\
\text { of accuracy, usefulness, worthiness and attractiveness. The results of the } \\
\text { effectiveness test conducted at SMA N } 1 \text { Tidore City showed that this guide was } \\
\text { effective in increasing the career planning of high school students. Given the } \\
\text { limitations of the research the researcher hopes that the next researcher will test the } \\
\text { effectiveness of other schools in the City of Tidore and be able to develop the local } \\
\text { wisdom of the City of Tidore to be applied to the Guidance and Counseling service }\end{array}$ \\
\hline & Abstrak: \\
\hline $\begin{array}{l}\text { Kata Kunci: } \\
\text { Perencanaan } \\
\text { karier, prinsip } \\
\text { hidup toma loa se } \\
\text { banari dan siswa } \\
\text { SMA. }\end{array}$ & $\begin{array}{l}\text { Tujuan penelitian ini adalah menghasilkan deskripsi isi dan format panduan } \\
\text { perencanaan karir berbasis prinsip hidup toma loa se banari yang layak untuk } \\
\text { membentuk siswa SMA merencanakan karirnya. Metode yang digunakan pada } \\
\text { penelitian ini adalah research and development dengan menggunakan tahapan dari } \\
\text { Borg and Gall. Instrumen yang digunakan pada penelitian ini adalah (1) instrumen } \\
\text { penilaian ahli (2) instrumen penilaian pengguna, dan (3) skala perencanaan karir. } \\
\text { Hasil akhir penelitian ini adalah produk yang merupakan buku panduan perencanaan } \\
\text { karir berbasis prinsip hidup toma loa se banari yang memenuhi unsur keberterimaan } \\
\text { yang terdiri dari aspek ketepatan, kegunaan, kelayakan, dan kemenarikan. Hasil uji } \\
\text { efektivitas yang dilakukan di SMAN } 1 \text { Kota Tidore menunjukkan bahwa panduan ini } \\
\text { efektif meningkatkan perencanaan karir siswa SMA. Mengingat keterbatasan } \\
\text { penelitian diharapkan agar peneliti selanjutnya melakukan uji efektivitas pada } \\
\text { sekolah-sekolah lain di Kota Tidore dan bisa mengembangkan kearifan local Kota } \\
\text { Tidore untuk diaplikasikan ke dalam layanan bimbingan dan konseling }\end{array}$ \\
\hline & $\begin{array}{l}\text { Edu Consilium: Jurnal Bimbingan dan Konseling Pendidikan Islam } \\
\text { Institut Agama Islam Negeri Madura, Indonesia }\end{array}$ \\
\hline
\end{tabular}

\section{PENDAHULUAN}

Bimbingan dan Konseling adalah upaya sistematis, objektif, logis dan berkelanjutan serta terprogram yang dilakukan oleh konselor atau guru Bimbingan dan Konseling untuk memfasilitasi perkembangan peserta didik/konseli untuk mencapai kemandirian dalam 
kehidupannya. Tujuan layanan bimbingan dan konseling membantu konseli mencapai perkembangan optimal dan kemandirian secara utuh dalam aspek pribadi, belajar, social, dan karir (Kementerian Pendidikan dan Kebudayaan Republik Indonesia, 2014). Peraturan tersebut menjelaskan bagaimana pentingnya layanan bimbingan konseling dalam mencapai standar kemandirian peserta didik dalam berbagai bidang.

Layanan bimbingan dan konseling salah satunya berperan pada perkembangan karir siswa. Agar siswa memiliki kemampuan untuk merencanakan karirnya maka sangat diperlukan layanan yang membantu untuk merencanakan karir di masa depan. Pemilihan jurusan di perguruan tinggi merupakan salah satu kegiatan perencanaan karir siswa di masa yang akan dating (Jung \& Lee, 2019). Ini sangat penting bagi siswa karena mereka mulai membentuk suatu jalur yang akan dilaluinya di kehidupan mendatang sebagai bentuk tugas perkembangan karir pada masa remaja. Hal ini menunjukkan bahwa pentingnya memilih jurusan yang tepat meskipun harus melalui proses yang tidak mudah. Pada periode ini banyak siswa yang merasa tidak yakin pada kemampuannya sendiri hingga akhirnya mengalami kebingungan dalam pengambilan keputusan karirnya.

Perencanaan karier berusaha membantu individu untuk memahami kondisi pribadinya (sifat/kepribadian, bakat dan minat, serta kelebihan dan kekurangan yang dimilikinya) serta memberikan gambaran tentang berbagai bidang minat karir di masa depan(Zacher et al., 2019). Perencanaan karir yang dimiliki oleh siswa berguna untuk pemilihan jenis studi lanjut, dan pemilihan rencana pekerjaan (Atmaja, 2014). Namun, yang terjadi sekarang ini masih banyak siswa SMA bingung dalam merencanakan karirnya. Hal tersebut disebabkan oleh beberapa hal yang salah satunya, yaitu: minimnya informasi dan kesadaran diri siswasiswi, guru BK dan orangtua tentang pentingnya perencanaan karir (Saidah, dkk., 2021).

Hasil penelitian terdahulu menunjukkan bahwa konsep diri sangat berpengaruh terhadap kesesuaian perencanaan karir individu dan lingkungan sangat berperan dalam pengembangan diri individu menentukan tujuan kariernya (Monje-Paulson et al., 2019).Perencanaan karir siswa yang jelas akan membantu individu mengembangkan ide-ide tentang siapa mereka dalam berperan disituasi yang berbeda berdasarkan pengamatan diri mereka sendiri yang unik, serta interaksi social dan umpan balik dari orang lain. Penggunaan nilai-nilai yang ada di masyarakat sebagai pilar identitas dapat memperkuat makna dan mendorong siswa bijak dalam merencanakan sesatu hal (Utami et al., 2018). Proses perkembangan konsep diri bersifat multidimensi, selanjutnya dijelaskan oleh Super dalam faktor-faktor perkembangan konsep diri dalam menentukan karier, yaitu: faktor internal yang 
terdiri dari: bakat, kebutuhan, nilai-nilai, inteligensi, minat, dan kepribadian. Sedangkan factor eksternal yaitu: teman, keluarga, masyarakat, sekolah, dan ekonomi.

Berdasarkan fenomena yang terjadi di lapangan sesuai dengan hasil wawancara penulis dengan guru BK maka penulis tertarik untuk mengadakan Penelitian dan Pengembangan Panduan Perencanaan Karier Berbasis Prinsip Hidup Toma Loa Se Banari bagi siswa SMA. Tujuan penelitian dan pengembangan ini adalah menghasilkan panduan perencanaan karir berbasis prinsip hidup Toma Loa Se Banari siswa SMA sebagai sarana yang dapat digunakan oleh konselor untuk dapat membantu siswa merencanakan karir yang dapat diterima secara teoritis dan praktis memenuhi aspek akseptabilitas meliputi ketepatan, kegunaan, kelayakan dan kemenarikan.

\section{METODE}

Penelitian ini merupakan penelitian pengembangan yang menggunakan model pengembangan Borg and Gall yang tahapnya disesuaikan dengan keperluan dan kondisi peneliti yaitu sampai tahap ke delapan (Gall et al., 2003). Pengembangan panduan perencanaan karir berbasis prinsip hidup toma loa se banari untuk siswa SMA dimulai dengan melakukan need assessment tentang perencanaan karir siswa SMA, kerangka panduan perencanaan karir, mengembangkan buku panduan perencanaan karir, kemudian melakukan pengujian awal kepada ahli budaya, bimbingan dan konseling serta ahli media. Setelah dilakukan revisi produk dilakukan uji pengguna kepada tiga konselor, dari hasil uji pengguna dilakukan revisi kembali dan setelah itu dilakukan uji kelompok kecil dengan 8 orang siswa SMA di SMAN 1 Kota Tidore.

Instrumen pengumpulan data pada pengembangan panduan berbasis nilai hidup toma loa se banari terdiri dari (1) skala penilaian ahli budaya, bimbingan dan konseling, dan media (2) skala penilaian calon pengguna, dan (3) skala perencanaan karir siswa SMA. Skala penilaian ahli dan pengguna diukur berdasarkan aspek ketepatan, kegunaan, kelayakan, dan kemenarikan. Data skor penilaian ahli dan pengguna dianalisis yang bersifat kuantitatif dianalisis menggunakan analisis validasi Aiken's yang menggunakan rentang skor 1-4 (Aiken, 1980). Data berupa masukan ahli masuk dalam data kualitatif yang akan dipakai untuk revisi produk.Subjek pada penelitian pengembangan panduan perencanaan karir berbasis prinsi hidup toma loa se banari siswa SMA terdiri dari (1) 2 ahli BK, 1 ahli media dan 1 ahli budaya, (2) 3 konselor, dan (3) 8 orang siswa SMA. 


\section{HASIL}

Produk yang dihasilkan pada penelitian pengembangan ini adalah panduan perencanaan karir berbasis prinsip hidup toma loa se banari siswa SMA yang memenuhi aspek akseptabilitas pada materi dan format. Susunan buku panduan ini terdiri dari tiga bab, bab pertama terdiri dari rasional, tujuan, sasaran pengguna dan sasaran layanan, media permainan roda berputar dan petunjuk pelaksanaan. Bab kedua terdiri dari prosedur umum perencanaan karir, prinsip hidup toma loa se banari, perencanaan karir berbasis hidup toma loa se banari, komponen toma loa se banari, peserta dan tugas konselor. Bab ketiga berisi tahap inti perencanaan karir berbasis prinsip hidup toma loa se banari yang terdiri dari eksplorasi karir, eksplorasi diri dan eksplorasi toma loa se banari, analisa potensi diri dan rencana karir dan analisa masalah karir dan problem solving. Bab keempat terdiri dari evaluasi skala perencanaan karir berbasis prinsip hidup toma loa se banari.

Pengujian yang dilakukan oleh ahli dan calon pengguna dijadikan sebagai acuan untuk mengetahui kelayakan produk panduan perencanaan karier berbasis prinsip hidup toma loa se banari siswa SMA teoritis dan praktis. Hasil penilaian ahli selanjutnya dihitung dengan menggunakan validitas Aiken V (Azwar, 1999) hasilnya sebagai berikut. Penilaian yang dilakukan oleh ahli media pembelajaran didasarkan pada aturan hukum yaitu, PP No 19 tahun 2005 pasal 43 ayat 5: "kelayakan isi, bahasa, penyajian, dan kegrafikan buku teks pelajaran dinilai oleh BNSP dan ditetapkan dengan Peraturan Menteri”. Badan Standar Nasional Pendidikan memiliki kriteria kegrafikan buku teks yang terdiri dari tiga aspek penilaian yaitu aspek ukuran panduan, desain kulit buku panduan dan desain isi buku panduan. Hasil penilaian ahli media mendapatkan indeks skor rata-rata 0.95 yang termasuk dalam kategori tinggi. Selanjutnya, hasil penilaian ahli bimbingan dan konseling terhadap isi materi panduan perencanaan karier berbasis prinsip hidup toma loa se banari siswa SMA mendaptkan indeks validitas sebesar 0.70 yang termasuk dalam kategori sedang. Hasil penilaian ahli budaya terhadap muatan nilai-nilai toma loa se banari pada panduan perencanaan karier berbasis prinsip hidup toma loa se banari siswa SMA mendapatkan skor indeks sebesar 0.75 yang termasuk dalam kategori sedang. Hasil penilaian calon pengguna terhadap isi materi panduan perencanan karier berbasis prinsip hidup toma loa se banari siswa SMA ini mendapatkan indeks skor sebesar 0.81 yang termasuk dalam kategori tinggi.

Selain mendapatkan penilaian kuantitatif panduan ini mendapatkan saran, masukan dan kritik dari para ahli dan pengguna. Berdasarkan hasil data-data secara kuantitatif dan kualitatif menunjukkan bahwa panduan perencanaan karier berbasis nilai hidup toma loa se 
banari telah memenuhi unsur akseptabilitas. Komentar, saran, kritik dan masukkan dari ahli dan pengguna menjadi acuan untuk melakukan revisi produk untuk perbaikan yang lebih baik.Adapun kritik, saran, masukkan dan komentar yang dijadikan acuan revisi produk dijelaskan pada table 1.

Tabel 1. Kritik, Saran, Masukkan dan Komentar Ahli dan Pengguna

\begin{tabular}{|c|c|c|c|}
\hline No & $\begin{array}{l}\text { Ahli dan Calon } \\
\text { Pengguna }\end{array}$ & Masukan & Revisi \\
\hline 1 & $\begin{array}{l}\text { Ahli bimbingan dan } \\
\text { konseling }\end{array}$ & $\begin{array}{l}\text { 1) Pada tahap pendahuluan } \\
\text { perlu ditambah sub bahasan } \\
\text { tentang pelaksanaan layanan } \\
\text { bimbingan kelompok pada } \\
\text { tabel. } \\
\text { 2) Pada bab II perlu dijelaskan } \\
\text { integritas toma loa se banari } \\
\text { dalam prosedur perencanaan } \\
\text { karir. } \\
\text { 3) Setiap pertemuan perlu ada } \\
\text { identitas atau scenario } \\
\text { (media, tujuan dan lain-lain) } \\
\text { 4) Waktu setiap pertemuan } \\
\text { perlu sesuai jam tatap muka } \\
\text { BK. } \\
\text { 5) Cerita dibuat lebih } \\
\text { komunikatif. }\end{array}$ & $\begin{array}{l}\text { 1) Bahasan tentang } \\
\text { pelaksaan } \\
\text { bimbingan } \\
\text { kelompok sudah } \\
\text { di tambahkan. } \\
\text { 2) Integritas toma } \\
\text { loa se banari } \\
\text { telah } \\
\text { dimasukkan ke } \\
\text { dalam prosedur } \\
\text { perencanaan } \\
\text { karir. } \\
\text { 3) Ditambahkan } \\
\text { kelengkapan dan } \\
\text { waktu pada } \\
\text { setiap } \\
\text { pertemuan. } \\
\text { 4) Cerita telah } \\
\text { direvisi }\end{array}$ \\
\hline 2 & Ahli budaya & $\begin{array}{l}\text { Prinsip hidup toma loa se banari } \\
\text { perlu diimplementasikan } \\
\text { secaralebih nyata dalam } \\
\text { kehidupan anak-anak SMA, } \\
\text { sehingga terbentuk karakter anak } \\
\text { SMA di Tidore sesuai prinsip } \\
\text { hidup toma loa se banari. }\end{array}$ & $\begin{array}{l}\text { Prinsip hidup toma } \\
\text { loa sebanari } \\
\text { dijelaskan sesuai } \\
\text { dengan kehidupan } \\
\text { siswa SMA pada } \\
\text { masa kini. }\end{array}$ \\
\hline 3 & Ahli media & $\begin{array}{l}\text { 1) Tata ulang pemenggalan kata } \\
\text { pada judul agar lebih indah } \\
\text { 2) Tata ulang sistem penomoran } \\
\text { 3) Pertajam warna yang kurang } \\
\text { kontras }\end{array}$ & $\begin{array}{l}\text { Pemenggalan kata } \\
\text { sudah diatur ulang, } \\
\text { penomoran juga } \\
\text { sudah ditata ulang } \\
\text { serta warna sudah } \\
\text { dipercerah agar } \\
\text { lebih bagus. }\end{array}$ \\
\hline 4 & Calon Pengguna & $\begin{array}{l}\text { 1) Ice breaking nya di tambah, } \\
\text { agar siswa tidak bosan } \\
\text { 2) Pengembangan teori dan } \\
\text { materi diperlukan agar dapat } \\
\text { meningkatkan pengetahuan } \\
\text { siswa tentang perencanaan } \\
\text { karir yang tepat }\end{array}$ & 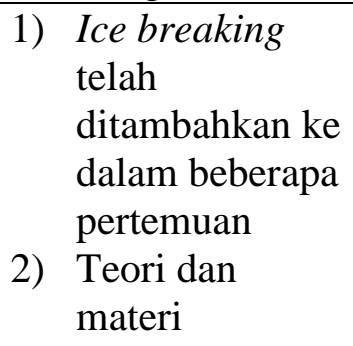 \\
\hline
\end{tabular}


perencanaan

karir telah

dijelaskan.

Nilai-nilai toma loa se banari yang dapat diinternalisasikan dalam diri siswa atau konseli untuk pengambilan keputusan karier dalam proses layanan bimbingan kelompok tersaji pada tabel 2 .

\section{Tabel 2. Internalisasi Nilai-Nilai Toma Loa Se Banari Siswa SMA}

No Internalisasi Nilai-Nilai Toma Loa Se Banari Siswa SMA

1 Mae Se Kalfino yang berarti malu dan takut, maknanya adalah konseli atau siswa mampu menanamkan nilai-nilai ini ke dalam diri dan konseli atau siswa menjadi pribadi yang malu dan takut kepada Tuhan dalam melakukan kesalahan dalam kehidupan kariernya.

2 Cing Se Cingeri yang berarti kejujuran, maknanya adalah konseli harus mampu menanamkan sikap jujur dalam bidang minat karier yang sudah dipilih dan dalama kehidupan sehari-hari.

3 Budi Se Bahasa yang berarti akhlak mulia, maknanya adalah konseli harus mampu menunjukkan akhlak mulia atau perilaku yang baik dalam bidang minat karier yang dipilih.

$4 \quad$ Ngaku Se Rasai yang berarti saling menghormati dan menghargai, ,maknanya adalah konseli mampu menunjukkan sikap saling menghormati dan menghargai antara sesama dalam bidang minat karier yang dipilih.

\section{PEMBAHASAN}

Penelitian dan pengembangan panduan perencanaan karier berbasis prinsip hidup toma loa se banari memberikan hasil berupa produk panduan perencanaan karier berbasis prinsip hidup toma loa se banari siswa SMA. Produk panduan ini telah memenuhi unsur kelayakan produk panduan yang telah tervalidasi secara teoritis oleh ahli media, ahli bimbingan dan konseling dan ahli budaya. Produk panduan ini juga telah memenuhi unsur kelayakan panduan yang telah tervalidasi secara praktisi oleh calon pengguna dan uji keefektifan produk. Produk ini menjawab kebutuhan para konselor akan kebutuhan layanan bimbingan dan konseling yang berbasis budaya. Konselor dituntut kepekaannya dalam budaya. Ini sejalan dengan pernyataan bahwa konselor wajib memiliki kompetensi multikultural yang meliputi kesadaran, pengetahuan serta keterampilan dalam budaya (“Sue1982," n.d.).

Ahli media memberikan penilaian kelayakan media atas bentuk dan desain panduan. Hasil penilaian ahli media menyatakan bahwa panduan perencanaan karier berbasis prinsip hidup toma loa se banari layak dengan validitas kelayakan pada angka 0.95 . Penilaian ahli 
media ini menunjukkan bahwa produk panduan telah memenuhi unsur kelayakan dari sisi format untuk digunakan sebagai sebuah media bagi guru BK. Secara fisik produk panduan telah memenuhi syarat ketentuan dari BNSP. Panduan memiliki standar ukuran yang telah dikriteriakan oleh BNSP yaitu salah satunya standar ukuran B5 $(182 \times 275) \mathrm{cm}$. Ukuran tersebut merupakan standar ISO dan JIS (BSNP, 2014). Ukuran B5 juga merupakan ukuran buku yang sedang dan mudah dibawa kemana saja (Sari, 2018). Bahan yang digunakan untuk cover buku panduan yaitu kertas ArtPaper 260 gram yang merupakan kertas yang menunjukkan hasil cetak yang bagus melalui cetak digital. Halaman isi panduan menggunakan kertas HVS 70 gram.

Kajian kelayakan panduan perencanaan karier berbasis prinsip hidup toma loa se banari sebagai media memiliki kelayakan format yang dideskripsikan sebagai berikut. Pertama, panduan disusun dengan sistematika sampul, ucapan terima kasih, daftar isi, bab I pendahuluan, bab II perencanaan karier berbasis prinsip hidup toma loa se banari, bab II prosedur perencanaan karier, bab VI evaluasi dan daftar rujukan. Kedua, panduan disusun menggunakan sistem penulisan baku, baik dari segi bahasa, penyajian tabel dan lain-lain, sesuai dengan kondisi pengguna yaitu para guru BK. Ketiga, panduan dilengkapi instrumen sebagai kelengkapan penyajian materi. Keempat, panduan di desain untuk menggambarkan isi materi yang merupakan muatan prinsip hidup toma loa se banari.

Penilaian isi materi bimbingan dan konseling dilakukan oleh dua orang ahli bimbingan dan konseling dan tiga orang calon pengguna. Para ahli bimbingan dan konseling memberikan penilaian kelayakan atas isi dalam materi dan prosedur panduan perencanaan karier berbasis prinsip hidup tomaloasebanari dalam panduan ini. Hasil penilaian dua ahli bimbingan konseling menyatakan bahwa panduan perencanaan karier berbasis prinsip hidup toma loa se banari siswa SMA layak dengan indeks validitas ahli sebesar 0.70 sedangkan penilaian yang dilakukan oleh calon pengguna mendapatkan skor validitas 0.81 . Penilaian isi materi bimbingan dan konseling ini menunjukkan bahwa produk panduan ini telah layak digunakan sebagai panduan yang memuat materi bimbingan dan konseling untuk digunakan oleh guru BK, namun terdapat beberapa perbaikan yang perlu dilakukan. Deskripsi kelayakan isi materi bimbingan dan konseling dalam panduan perencanaan karier berbasis prinsip hidup toma loa se banari sebagai berikut. Pertama, sampul panduan menunjukkan isi materi bimbingan konseling dan gambaran singkat rasional pentingnya panduan ini. Kedua, bagian I pendahuluan menyajikan materi urgensi secara ringkas pengembangan perencanaan karier berbasis prinsip hidup toma loa se banari siswa SMA, tujuan panduan dan sasaran pengguna. 
Ketiga, bagian II perencanaan karier berbasis prinsip hidup toma loa se banari. Bagian ini memaparkan prosedur umum perencanaan karier, prinsip hidup toma loa se banari, perencanaan karier bebrbasis prinsip hidup toma loa se banari, peserta dan tugas konselor. Keempat, bagian III prosedur perencanaan karier. Pada bagian ini dipaparkan secara terperinci langkah-langkah pelaksanaan perencanaan karier berbasis prinsip hidup toma loa se banari. Kelima, bagian IV evaluasi, bagian ini memuat instrumen-instrumen yang digunakan sebagai alat evaluasi pelaksanaan layanan.

Ahli budayawan Tidore memberikan penilaian kelayakan atas materi dalam penyajian dan pemuatan nilai-nilai toma loa se banaripada langkah-langkah perencanaan karier dalam panduan. Hasil penilaian ahli budayawan Tidore menyatakan bahwa panduan perencanaan karier berbasis prinsip hidup toma loa se banari bagi siswa SMA layak dengan indeks validitas sebesar 0.75 . Penilaian ahli budayawan Tidore menunjukkan bahwa produk panduan ini telah layak digunakan oleh guru bimbingan dan konseling sebagai panduan yang bermuatan nilai-nilai toma loa se banari. Kelayakan isi nilai-nilai toma loa se banari mendukung kelayakan isi materi perencanaan karier yang menunjukkan kelayakan perencanaan karier berbasis prinsip hidup toma loa se banari. Sisi lain yang diperkuat oleh hasil penilaian layak oleh ahli budaya Tidore adalah internalisasi nilai-nilai toma loa se banari ke dalam langkah-langkah perencanaan karier. Internalisasi nilai-nilai toma loa se banari dalam panduan ini termasuk dalam kategori layak dengan kriteria sebagai berikut. Pertama, panduan didesain dengan menggambarkan makna prinsip hidup toma loa se banari. Penggambaran tersebut ditunjukkan melalui desain cover buku panduan yang merupakan gambar gunung Tidore dan gambar Kedaton kesultanan Tidore. Kedua, bagian sampul belakang panduan yang didesain dengan memaparkan kutipan yang memiliki makna dari prinsip hidup toma loa se banari. Ketiga, prinsip hidup toma loa se banari diimplementasikan ke dalam tahap-tahap perencanaan karier.

Hasil uji keefektifan produk panduan semakin memperkuat bukti kelayakan produk dari sisi praktis. Pengujian keefektifan produk dilakukan melalui pelaksanaan layanan bimbingan kelompok dengan materi perencanaan karier berbasis prinsip hidup toma loa se banari bagi siswa SMA. Adanya kesetaraan dan kerjasama (kerja tim) antara konselor dan konseli. Baik konselor maupun konselor menjunjung tinggi nilai kesetaraan. Konselor bukan tokoh dominan dalam layanan bimbingan kelompok ini, mereka juga tidak menggurui. Konselor bekerja dengan konseli untuk membantunya memiliki perencanaan karir yang matang dengan memasukkan nilai toma loa sebanari dalam layanan bimbingan kelompok ini 
.Hal ini sesuai dengan pendapat (Hidayah \& Ramli, 2017)yang menjelaskan untuk mengubah kognisi dan perilaku konseli untuk menyelesaikan masalah perlu adanya batas nilai budaya.Pengujian yang dilakukan terhadap delapan orang siswa menunjukkan adanya dampak peningkatan pencapaian skor perencanaan karier siswa. Hal ini diperkuat dengan pendapat bahwa konselor tidak boleh melupakan nilai-nilai budaya dimana konseli berada, karena proses pertimbangan nilai dengan menggunakan budaya di sekitar masyarakat akan lebih efektif dan mudah di pahami oleh masyarakat itu sendiri (Pedersen, 2002; Sari et al., 2018, 2020; Sari \& Bulantika, 2019; Sumari et al., 2008). Penelitian lain yang menyatakan dengan adanya layanan berbasis budayadapat digunakan sebagai salah satu cara seseorang mengekspresikan perasaannya untuk memfasilitasi perbaikan diri, mengatasi permasalahan ataupun mengambil keputusan dan perbaikan hubungan interpersonal dengan berbagai situasi permasalahan(Hambali, 2016). Ini menunjukkan bahwa nilai-nilai toma loa se banari sangat tepat diaplikasikan ke dalam layanan bimbingan khususnya perencanaan karier siswa SMA.

Keunggulan yang pertama adalah panduan ini praktis dan lengkap, Karena tidak hanya memuat prosedur pelaksanaan perencanaan karier namun terdapat materi tentang nilainilai toma loa se banari. Keunggulan yang kedua yaitu mempertimbangkan nilai-nilai toma loa se banari karena menjadi nilai tambah untuk siswa dalam mengetahui nilai-nilai budaya Tidore. kearifan local dapat membantu siswa mencapai tujuan pembelajaran dan career mereka (Dewi et al., 2017). Secara praktis keunggulan penelitian pengembangan produk panduan perencanaan karier berbasis prinsip hidup toma loa se banari ini adalah memfasilitas guru BK untuk melaksanakan bimbingan kelompok secara lebih terstruktur dan membantu siswa dalam meningkatkan perencanaan karier berbasis prinsip hidup toma loa se banari.Para pengguna layanan konseling di Indonesia diharapkan tidak hanya untuk belajar dan mempraktikkan teori dan pendekatan yang diungkapkan oleh negara-negara Barat, tetapi juga mampu merumuskan paradigma baru dengan bukti empiris dan rasional dari konseling budaya Indonesia yang khas dengan dasar kekhasan budaya Indonesia. Konselor Indonesia perlu mengembangkan kesadaran diri mereka sendiri tentang sifat manusia Indonesia dengan tidak meminjam "pakaian" konseling Barat. Konselor dituntut memiliki kepekaan budaya dan kemampuan untuk melepaskan diri dari bias budaya (All Habsy et al., 2017). 


\section{SIMPULAN}

Produk panduan yang dikembangkan memenuhi unsur keberterimaan panduan yang meliputi kelayakan isi dan format. Produk panduan yang telah dikembangkan memiliki bukti keefektifan perencanaan karier berbasis prinsip hidup toma loa se banari yang memberikan perubahan signifikan terhadap peningkatan perencanaan karier siswa SMA. Bukti keefektifan ini menunjukkan bahwa panduan perencanaan karier berbasis prinsip hidup toma loa se banari bagi siswa SMA telah layak digunakan sebagai panduan bimbingan dan konseling untuk diterapkan terhadap siswa yang telah memenuhi kelayakan teoritis dan praktis.

Saran untuk Guru BK sebagai pengguna produk, disarankan untuk mempelajari dengan baik sajian materi dalam panduan ini. Guru BK disarankan untuk berdiskusi dengan kolega terkait pemahaman materi dan pelaksanaan perencanaan karier berbasis prinsip hidup toma loa se banari. Pada proses pelaksanaan layanan bimbingan kelompok, guru BK juga di sarankan untuk melibatkan kolega sebagai peer-review yang dapat menilai dan memberikan masukan atas proses pelaksanaan layanan bimbingan kelompok yang dilakukan. Saran yang diberikan kepada peneliti lebih lanjut dilakukannya pengujian lebih lanjut terkait keefektifan produk terhadap siswa-siswa di sekolah yang lain di Kota Tidore

\section{DAFTAR RUJUKAN}

Aiken, L. R. (1980). Content validity and reliability of single items or questionnaires. Educational and Psychological Measurement, 40(4), 955-959. https://doi.org/10.1177/001316448004000419

All Habsy, B., Hidayah, N., Boli Lasan, B., \& Muslihati, M. (2017). A Literature Review of Indonesian Life Concept Linuwih Based on the Teachings of Adiluhung Raden Mas Panji Sosrokartono. November. https://doi.org/10.2991/icet-17.2017.10

Atmaja, T. T. (2014). Upaya Meningkatkan Perencanaan Karir Siswa Melalui Bimbingan Karir dengan Penggunaan Media Modul. PSIKOPEDAGOGIA Jurnal Bimbingan Dan Konseling, 3(2), 57. https://doi.org/10.12928/psikopedagogia.v3i2.4466

Azwar, S. (1999). Penyusunan skala psikologi. Pustaka pelajar.

Dewi, I. N., Poedjiastoeti, S., \& Prahani, B. K. (2017). ELSII Learning Model Based Local Wisdom to Improve Students' Problem Solving Skills and Scientific Communication. International Journal of Education and Research, 5(1), 107-118.

Gall, M. D., Gall, J. P., \& Borg, W. R. (2003). Educational Research. In Educational Research: An introduction (p. 683).

Hambali, I. (2016). Model Dialog “4D” Untuk Meningkatkan Kesadaran Multi Kultural Siswa Sma Di Kota Malang. Jurnal Kajian Bimbingan Dan Konseling, 1(3), 95-103. https://doi.org/10.17977/um001v1i32016p095

Hidayah, N., \& Ramli, M. (2017). Need of Cognitive-Behavior Counseling Model Based on Local Wisdom to Improve Meaning of Life of Madurese Culture Junior High School Students. 128(Icet), 301-307. https://doi.org/10.2991/icet-17.2017.53

Jung, J., \& Lee, S. J. (2019). Exploring the factors of pursuing a master's degree in South Korea. Higher Education, 78(5), 855-870. 
Kementerian Pendidikan dan Kebudayaan Republik Indonesia. (2014). Peraturan Menteri Pendidikan dan Kebudayaan Nomor 111 tahun 2014 Tentang Bimbingan dan Konseling pada Pendidikan Dasar dan Menengah. 1-38.

Monje-Paulson, L. N., Olson, A. B., Pizzolato, J. E., \& Sullivan, K. A. (2019). Adult Learner Career Trajectories: Vocational Self-Concept Development in CalWORKs Community College Students. College Student Affairs Journal, 37(1), 68-82.

Pedersen, P. B. (2002). The Making of a Culturally Competent Counselor. Online Readings in Psychology and Culture, 10(3), 1-13. https://doi.org/10.9707/2307-0919.1093

Saidah, I., Atmoko, A., \& Muslihati, M. (2021). Aspirasi Karier Generasi Milenial. Edu Consilium: Jurnal Bimbingan dan Konseling Pendidikan Islam, 2(1), 62-89.

Sa'idah, I. (2018). Memprediksi Minat Karier dan Pilihan Aspirasi Terhadap Pertimbangan Pilihan Karier Berdasarkan Social Cognitive Career Theory (SCCT). JKI (Jurnal Konseling Indonesia), 3(2), 48-56.

Sari, P. (2018). Pengembangan Panduan Pertimbangan Nilai Ajaran Nengah Nyapur Etnis Lampung Untuk Mereduksi Perilaku Bulying Siswa SMK. 1095-1099.

Sari, P., \& Bulantika, S. Z. (2019). KONSELING INDIGENOUS BERBASIS TATA NILAI BUDAYA LAMPUNG “PIIL PESENGGIRI ” DALAM PEMBENTUKAN. 9(2), 190199.

Sari, P., Suryawati, C. T., \& Bulantika, S. Z. (2020). Internalisasi Nilai-nilai Piil Pesenggiri untuk Mencegah Perilaku Bullying Siswa SMK. 6(1), 1-7.

Sari, P., Triyono, T., \& Mappiare, A. (2018). Panduan Pertimbangan Nilai Ajaran Nengah Nyappur Etnis Lampung untuk Mereduksi Perilaku Bullying Siswa SMK. Jurnal Pendidikan: Teori, Penelitian, Dan Pengembangan, 3(8), 1095-1099.

Sue1982. (n.d.). The Counseling Psychologist, 45-52(June).

Sumari, M., Jalal, F., \& Idris, U. (2008). Cultural issues in counseling: An international perspective. Counselling, ..., 4(1), 24-34.

Utami, S. D., Efendi, I., Dewi, I. N., Ramdani, A., \& Rohyani, I. S. (2018). The study of local wisdom of ethnic sasaks in development of biology instructional learning program (P3Bio) based on 21st century skills. Mathematics, Informatics, Science, and Education International Conference (MISEIC 2018).

Zacher, H., Rudolph, C. W., Todorovic, T., \& Ammann, D. (2019). Academic career development: A review and research agenda. Journal of Vocational Behavior, 110, 357373. 